\title{
Laboreal
}

Volume $2 \mathrm{~N}^{\circ} 1$ | 2006

Varia

\section{La formación humana entre el concepto y la experiencia de trabajo : elementos para una pedagogía de la actividad}

A formação humana entre o conceito e a experiência de trabalho : elementos para uma pedagogia da actividade

La formation humaine entre le concept et l'expérience de travail : éléments pour une pédagogie de l'activité

Human training between the concept and work experience : elements to a pedagogy of the activity

\section{Daisy Cunha}

\section{OpenEdition}

Journals

Edición electrónica

URL: http://journals.openedition.org/laboreal/13736

DOI: 10.4000/laboreal.13736

ISSN: 1646-5237

Editor

Universidade do Porto

Referencia electrónica

Daisy Cunha, «La formación humana entre el concepto y la experiencia de trabajo : elementos para una pedagogía de la actividad », Laboreal [En línea], Volume 2 No1 | 2006, Publicado el 01 julio 2006, consultado el 24 septiembre 2020. URL : http://journals.openedition.org/laboreal/13736 ; DOI : https://doi.org/10.4000/laboreal.13736

Este documento fue generado automáticamente el 24 septiembre 2020.

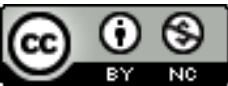

Laboreal está licenciado com uma Licença Creative Commons - Atribuição-NãoComercial 4.0 Internacional. 


\title{
La formación humana entre el concepto y la experiencia de trabajo : elementos para una pedagogía de la actividad
}

\author{
A formação humana entre o conceito e a experiência de trabalho : elementos \\ para uma pedagogia da actividade \\ La formation humaine entre le concept et l'expérience de travail : éléments pour \\ une pédagogie de l'activité \\ Human training between the concept and work experience : elements to a \\ pedagogy of the activity
}

\section{Daisy Cunha}

\section{REFERENCIA}

Cunha, Daisy (2005). La formation humaine entre le concept et l'experience du travail : éléments pour une pédagogie de l'activité. Tese de Doutoramento. Université de Provence, Aix-en-Provence.

NOTA DEL EDITOR

Manuscrito recibido en : abril/2006

Aceptado tras peritage en : junio/2006 


\section{Un retorno sobre la problemática relación entre trabajo y educación.}

1 La idea de que trabajar educa está presente en el ideario pedagógico brasileño configurando formas institucionales, prácticas pedagógicas y reflexiones teóricas. La tesis interroga las dimensiones educativas de la experiencia de trabajo y con tal propósito no podría abandonar inversiones prácticas entre el polo de la gestión del trabajo, el polo del mercado y el polo de la politea donde se inscriben las normas educativas. Analizando la reciente evolución histórica de las políticas educacionales oficiales pudimos constatar separación radical entre experiencias de trabajo y educación. Paralelamente y en sentido contrario, propuestas implementadas por organizaciones de la sociedad civil articulaban experiencia de trabajo y educación, reforzando la idea del "trabajo como principio educativo": Movimiento de los Sin Tierra (MST) ; Programa de Formación Integrar (CNM/ CUT) ; Programa de Educación de Trabajadores (PET). De ese cuadro empírico fuimos reenviados al campo de las ideas pedagógicas en la producción teórica educacional brasileña donde verificamos el problema tratado en un doble sentido: crítica del trabajo y de la escuela bajo el capitalismo y afirmación del trabajo como principio educativo. En esa literatura, el trabajo se toma en su definición general o abstracta lo que dificulta comprender que él puede ser principio educativo. ¿Cómo puede el trabajo ser constituyente y organizador de los procesos de producción enajenantes bajo el capitalismo y al mismo tiempo elemento constituyente de lo humano? ¿Cómo puede ese trabajo que criticamos las dimensiones enajenadas bajo el capitalismo ser reapropiado por programas de formación en cuanto experiencia con potencialidades humanizadoras?

2 Además de esa aporia en la literatura brasileña, en la historia de las ideas pedagógicas encontramos tres momentos de aproximación entre trabajo y educación : trabajo del espíritu (Kant); resultado de la interacción en el juego (Educación Nueva); "producción" y trabajo manual (socialistas). También estas últimas producciones analizadas se revelan incapaces de incorporar la experiencia del trabajo real, del trabajo concreto como elemento de formación y, por lo tanto, dejan lagunas para responder a nuestra problemática de tesis: una pedagogía que se inscribe en la experiencia del trabajo lugar de un actuar que educa.

\section{Praxis o actividad : a propósito de la actuación humano}

3 Hemos sido llevados a interrogar el propio concepto de trabajo en varios autores para comprendernos en que sentido él podría ser comprendido como elemento de formación humana.

Con Kant vimos una concepción de actuación que es trabajo - actividad - de nuestra facultad de conocer. Este actuar asocia sujeto y objeto en una dialéctica sin fin, restringiendo estos dos polos en una relación tensa como condición del conocer. Pero la actividad de conocer hace su trabajo entre el entendimiento y la sensibilidad, sin que podamos controlarla, encuadrarla. El hombre es activo en el conocer y en el actuar moral. Este actuar moral reproduce la práctica como dominio de un trabajo sobre si, según imperativos categóricos. La praxis se inscribe en el dominio de la moral y no en 
el campo del conocer. Entre tanto, si adquirimos con Kant la idea de que la actividad infringe todas las fronteras siendo imposible encuadrarla, no hay vinculación entre actividad humana y experiencia del trabajo real.

5 Marx retoma el concepto de actividad situándola en el espacio y en el tiempo en un equilibrio frágil entre sujeto/objeto (Tesis I Feuerbach) [1]. En O Capital (Cap V), el término actividad aparece componiendo el proceso de trabajo, junto con el objeto y los instrumentos: actividad teniendo en vista una finalidad. Marx permanece lectura imprescindible porque ha elevado el trabajo a la categoría filosófica central. Sus aportaciones para una comprensión del trabajo como actividad humana son profundizadas por Gramsci para quien el trabajo es principio educativo por su potencial para formación de nuevas subjetividades. Hay la idea de que por el trabajo el hombre encuentra la vía de la transformación social, lugar de articulación del sujeto colectivo de "praxis revolucionaria", pero no se recurre al trabajo real en cuanto actividad hic et nuc. Lukács también rescata y profundiza esa cuestión en Marx: el trabajo es protoforma de otras actividades humanas y funda el ser social. Él es clave para comprender el proceso de hominización, forma original de praxis humana y "modelo ontológico de otras relaciones sociales". Hay, entre tanto, una dificultad de articular trabajo y praxis, pues aquél estaría inmerso en el cotidiano y solamente se elevaría a la condición de praxis cuando convertido en actividad humana consciente, lo que parece configurar dos ontologías en Lukács. Estos dos últimos planteamientos teóricos toman el trabajo en su definición general y no como trabajo concreto, donde la ausencia de contenido real de trabajo en sus dimensiones contradictorias y "encarnadas". En esa perspectiva encontramos una economía política de la educación y, aunque aprendamos la importancia de las bases materiales como determinantes para la formación humana, pero no comprendemos lo educativo del trabajo real.

6 Una profundización del papel desempeñado por el trabajo en el desarrollo humano puede ser encontrada en Vygotski y en Leontiev que fundamentan el desarrollo humano en el uso del instrumento y del lenguaje herramientas fundamentales para el desarrollo de las funciones superiores en el hombre. El desarrollo humano sería producto del entrelazar de dos procesos distintos y combinados: filogénesis y ontogénesis. Un componente material determina y constituye la actividad humana configurada en un proceso dialéctico sujeto/objeto. Por la "interiozación", uso y manipulación de objetos, instrumentos, herramientas, originan la conciencia en el curso de la filogénesis humana - hominisación del psiquismo. Por la educación ocurre la apropiación de las adquisiciones del desarrollo histórico de las actitudes humanas a través de las relaciones establecidas con otros hombres. Pero si ese proceso parece una "socialización", Leontiev interpone la dialéctica del sentido y del significado para mostrar que no podemos pensar la relación hombre/ medio social como una adaptación.

7 A su vez, Lucien Sève contribuye retomando la VI Tesis de Feuerbach para comprender la constitución de la individualidad humana por un proceso que denomina "excentración" : el hombre se forma en las experiencias en las cuales emplea su tiempo de vida y trabajo. Se introduce así la cuestión del "je" abriendo vías para plantear el sujeto de la actividad en el trabajo, perspectiva presente en planteamientos del trabajo en la producción francesa contemporánea. 


\section{El trabajo entre actividad, acto o acción}

8 En planteamientos contemporáneos del trabajo cuyo interés son las relaciones entre vida concreta en el trabajo y vida psíquica, el telón de fondo es un trabajo en transformación, marcado por una creciente degradación, desempleo, profundización de las formas de racionalización y explotación nuevas con consecuencias renovadas sobre la salud en general y sobre la vida mental y psíquica en especial. Dejours puntúa el sufrimiento psíquico en el trabajo enraizándolo en la negación de una subjetividad construida en la primera infancia. La incorporación del término actividad ocurrió, entre tanto, asociada a la poiesis, separada de la praxis. Mendel retoma Winnicott a propósito de una "zona transicional" que antecede la fase de constitución del sujeto psicoanalítico. El acto es alteridad, relación con el otro, la sociedad y la naturaleza. Indica toma de actitud frente a las circunstancias, realización de nuestros proyectos de acción. Esa concepción permite pensar la experiencia del sujeto a través de su acto de trabajo como experiencia educativa. Los actos no son sin consecuencia sobre las circunstancias y para el sujeto del acto.

Clot profundiza nuestro entendimiento sobre lo que sea la actividad humana de trabajo retomando las aportaciones de Sève, Vygotski y Leontiev. Para este autor, el trabajo es dirigido por motivos del sujeto, por objetivo de la tarea y por otro del trabajo. La actividad del sujeto se forma en esa relación triádica que en retorno, forma al sujeto de la actividad. El sujeto es el producto del desarrollo de sus actividades en medios en los cuales él interactúa. Pero actividad realizada no es la integralidad de la actividad del sujeto, lo real de la actividad hace referencia a lo que no hacemos; que queremos hacer sin conseguir; que podríamos haber hecho y no hicimos; que nosotros podemos hacer en otro lugar ; que hacemos para que no hagamos lo que podría ser hecho. El trabajo es el lugar de una experiencia constitutiva del "je", pudiendo ser objeto de una "clínica de la actividad" que contribuye para el desarrollo del individuo en el curso de su historia. Tal como en Leontiev, la acción es reintegrada como manifestación exterior de la actividad.

10 Además del rescate de las dimensiones simbólicas en la experiencia de trabajo, el planteamiento ergológico de Yves Schwartz inscribe esa actividad en un "corpo-si" cuya actividad industriosa es vida actuando en medios de trabajo. Ese "corpo-si" se coloca en la frontera entre lo biológico, neuropsicológico, psíquico e histórico-cultural.

11 El trabajo sería realidad compleja y multidimensional (económica, jurídica, ética, etc.) que debe ser observada con lupa por el prisma de la actividad singular. En cuanto experiencia, implica el sujeto en sus múltiples dimensiones vida vivida en el escuadro de un espacio-tiempo determinado, fuente de (re)trabajo en permanencia. Por el trabajo el hombre hace experiencia de su tiempo y de si mismo, es usado por otro y hace uso de si mismo en un juego dialéctico sin fin. Experiencia que implica un trabajo y (re)trabajo de valores y saberes en permanencia en una génesis que reconstituye infinita y microscópicamente el espacio socio-cultural. Él implica un "trabajo sobre si", un "uso de si por si mismo y por otro". Manifestación de vida humana, el trabajar es portador de una pluralidad de "dramáticas del uso de si" que cruzan el "corpo-si" exigiendo de estos la creación de sinergias entre las múltiples dimensiones que lo integran : cuerpo/alma; hacer/valores; verbal-no verbal ; consciente/no consciente ; individual/colectivo... En esta perspectiva encontramos espacio para pensar la actividad de trabajo siempre y en parte como experiencia educativa, como lugar de 
posibles aprendizajes y no aprendizajes de todo tipo. El hombre se hace por la experiencia de su actividad industriosa, en su relación con el mundo. Él hace así prueba de su plasticidad, renovándose a cada acto, desarrollando nuevas competencias para vivir en un proceso siempre inacabado. Él está en constante venir a ser por el conjunto de sus actos encarnados y configurados en trabajo sobre el medio. Actos cargados de sentido, de técnica, de "lógica", de saberes diversos que se presentan en el terreno del trabajo real. Tales actos son portadores de cambios continuos en el mundo recentramiento infinitesimal. La actividad de trabajo así comprendida trae en si una dimensión gnoseológica, pues es fuente de producción de nuevos saberes; una dimensión axiológica puesto que es fuente de un trabajo de valores; y porque constitutiva del desarrollo humano, portadora de una dimensión ontológica.

Al mismo tiempo, las experiencias que el hombre hace de si en el trabajo están asociadas a las experiencias hechas en otras vivencias. Ellas se enraízan en la historia profesional y personal, integrando la formación de la persona, su experiencia de vida, su patrimonio vivido. Pero lo que permite observar las dimensiones educativas postergando toda actividad de trabajo, nos constriñe a lo singular de las situaciones observadas para extraer tal contenido educativo del medio de las experiencias que hacen los hombres en su trabajo real. Para hacer frente a la infidelidad del medio, la actividad industriosa debe reconfigurar y renormalizar aprendizajes cristalizadas bajo la forma de experiencias y/o conocimientos males o menos formalizados y/o interiorizados. En ese proceso se inscriben las dimensiones educativas del actuar humano. Somos llevados a aprehender el fenómeno educativo en su génesis, pudiendo fundamentar una pedagogía que se ancla en el acto de trabajar. Si la educabilidad es una propiedad imposible de eliminar de la actividad humana, los aprendizajes son a su vez inseparables del vivir y del trabajar, inscribiéndose en el prolongamiento de la vida. Ellas aprenden del hombre y el hombre el trabajo de la vida.

\section{BIBLIOGRAFÍA}

Arroyo, M. (1991). Revendo os vínculos entre trabalho e educação : elementos materiais da formação humana. In Tomaz T.Silva (Org.) Trabalho, educação e prática social - por uma teoria da formação humana (pp. 163-216). Porto Alegre : Artes Médicas, Série Educação : Teoria e Crítica.

Bertocchi, J.-L. (1996). Marx et le sens du travail. Paris : Editions Sociales.

Charlot, B. (2003). Educação, trabalho : problemáticas contemporâneas que convergem. Cuiabá : UFMT.

Clot, Y. (1992). Le travail entre activité et subjectivité. Tese de Doutoramento. Université de Provence, Aix-en-Provence.

Dejours, C. (1993). Travail et usure mentale. Essai de psychologie du travail. Paris : Bayard Editions.

Gramsci, A. (1977). Cahiers de prision. vol. I, II, III, IV, V. Paris : NRF/Editions Gallimard. 
Kant, E. (2000). Critique de la raison pratique. (6a. ed.). Paris : PUF. Leontiev, A. (1984). Activité, conscience, personnalité. Paris : Editions du Progrès.

Lukács, G. (1979). Ontologia do ser social. Os princípios ontológicos de Marx. São Paulo : Ciências Humanas.

Marx, K. (1982). Thèses sur Feuerbach. In Karl Marx Philosophe. Paris : Gallimard, Collection Folio Essais.

Marx, K. (1989). O Capital. (12a ed.). Rio de Janeiro : Editora Bertrand do Brasil.

Mendel, G. (1998). L'acte est une aventure - du sujet métaphysique au sujet de l'acte-pouvoir. Paris : Editions La Découverte.

Schwartz, Y. (1992). Travail et Philosophie - convocations mutuelles. Toulouse : Editions Octarès. Schwartz, Y. (1988). Expérience et connaissance du travail. Paris : Messidor/Editions Sociales Schwartz, Y. (2000). Le paradigme ergologique ou un métier de philosophe. Toulouse : Octarès Editions.

Sève, L. (1969). Marxisme et théorie de la personnalité. Paris : Editions Sociales.

Vygotski, L.S. (1997). Pensée et langage. (3a ed.). Paris : La Dispute, 1997.

\section{NOTAS}

1. Las Tesis sobre Feuerbach fueron redactadas por Marx entre Mayo y Junio de 1845. Escritas en la forma de 11 notas, traen las posiciones de Marx cuanto a Hegel, Feuerbach, la sociedad burguesa y la revolución comunista. Fueron editadas póstumamente por Engels en1888 como anexo en la obra A Ideología Aemana. Cf : LABICA, G. Karl Marx Les thèses sur Feuerbach, Paris, PUF, 1987.

\section{AUTOR}

\section{DAISY CUNHA}

Universidade Federal de Minas Gerais - Faculdade de Educação Avenida Marte, nº 151, bloco 6, Apartado 302 - Brasil

daisycunha@uol.com.br 